After this session, attendees should be able to discuss various ways community trauma can manifest at the community level. During this session, we will briefly describe the findings of the study and present the emerging framework., along with examples of communities that are developing and implementing community level strategies. Prevention Institute will then facilitate a peerto-peer discussion exploring how community level trauma shows up in communities, and emerging resilience strategies to prevent and address it.

Conclusions The community trauma framework has implications for practitioners, researchers, and advocates developing strategies to improve safety by overcoming community-level trauma as a barrier to successful injury prevention.

\section{INTREGRATING STRATEGY TO TACKLE TRAFFIC ACCIDENTS IN BANPHAI DISTRICT, KHON KAEN PROVINCE, THAILAND}

${ }^{1}$ Adun Bamrung, ${ }^{1}$ Jirawan Kijlerdpornpairoj, ${ }^{1,2}$ Rapeepong Suphanchaimat, ${ }^{1}$ Prayoon Kowit. ${ }^{1}$ Banphai Hospital, Khon Kaen, Thailand; ' ${ }^{2}$ International Health Policy Program, Ministry of Public Health, Thailand

\subsection{6/injuryprev-2016-042156.623}

Background Banphai district is the major economic area in Khon Kaen province where traffic accidents often occur. The numbers of injuries visiting Banphai hospital varied between 1,800 and 2,040 cases/year, with about 30 deaths/year. To tackle this problem, the 'Managing Information System' (MIS) team was set up in 2009.

Description of problems and proposed solution Banphai hospital staff are the founding members. The nature of MIS is action research. Soon after its inception, the team gradually included police, the Department of Highways (DOH), the Department of Land Transport (DOLP), commerce groups, and other stakeholders. The 5E (Engineering, Enforcement, Education, Emergency, and Evaluation) and PDCA principles (Plan-Do-Check-Act) are applied. Each authority is responsible for different 'E', eg. the $\mathrm{DOH}$ for road engineering and the DOLP for educating drivers. The reporting systems between authorities were harmonised.

Effects/changes About $80 \%$ of traffic accidents related deaths are due to risky behaviours of the riders/drivers, while unsafe environments account for the rest 20\%. Some concrete measures (both long run and short run policies) were proposed. Examples of the measures are (1) establishing clear traffic signs in risky junctions, (2) closing the U-turn points where clashes often occurred, and (3) an instigation of Memorandum of Understanding (MOU) between authorities for campaigning helmet use. Since 2011, the incidence of traffic accidents related deaths has declined for about one third. It is estimated that had the MIS not been established, the injuries would have been risen by 81 cases/ year. The MIS is also successful in reducing alcohol related traffic injuries by about $6 \%$ (28 cases/year).

Conclusions The MIS working system is a beneficial lesson for other countries to learn how to harness local resources and seek coordination from stakeholders for preventing traffic accidents. Open-mindedness, trust and endurance are key success factors.

\section{HEALTHY NIGHT IN COIMBRA: PRIMARY PREVENTION PROJECT IN EDUCATIONAL CONTEXT}

${ }^{1}$ Filipa Sola, ${ }^{2}$ Paulo Simões, ${ }^{2}$ Alexandre Fernandes, ${ }^{3}$ João Redondo. ${ }^{1}$ Phychologist at the Centre for Prevention and Treatment of Psychological Trauma, Department of Psychiatry of Coimbra Hospital and Universitary Centre, Portugal; ${ }^{2}$ Nurse at the Centre for Prevention and Treatment of Psychological Trauma, Department of Psychiatry of Coimbra Hospital and Universitary Centre, Portugal; ${ }^{3}$ Coordinator at the Centre for Prevention and Treatment of Psychological Trauma, Department of Psychiatry of Coimbra Hospital and Universitary Centre, Portugal

\subsection{6/injuryprev-2016-042156.624}

Background Night recreation plays an important role for young people but it has, sometimes, an intrinsic association to risk factors in areas such as sexuality, violence, road driving and consumption of alcohol or other substances. The influence of these risk behaviours in health status and life quality of young people has been widely documented in literature; documentation, monitorization and intervention in these behaviours has been considered by healthcare organisations as a public health priority. A survey conducted by European Institute of Studies on Prevention, Portugal (Coimbra, 2014), reports that today there is more violence and aggression in nightlife (60\%), more cases of intoxication (70\%), higher consumption of illegal drugs (43\%) and sex under the influence of alcohol (65\%).

Methods Sensibilization activities, on the scope of primary prevention, aimed for students from secondary schools (aged between 14 and 18), with emphasis on the following topics: consumption of alcohol and other psychoactive substances, violence, sexual risk behaviour and night road accidents. Sample: 235 students, 12 classes. A questionnaire was applied at the beginning of the second scholar period in order to characterise and understand the behaviours of the students and in the end of the third scholar period in order to assess the impact of our intervention.

Results We found that majority of the students increased knowledge in the addressed thematics. This methodology enables to introduce a new narrative on youngsters and developing a new perception of these thematics.

Conclusions Focusing the prevention idea and considering the premature beginning of risky behaviour, it is essential the intervention at younger ages, privileging the school context, which will be enhanced by the multidisciplinary and multisectoral network approach. We believe that early investment in these problematics represents an additional contribution to the promotion of healthy nights and safe communities.

\section{A TYPOLOGY FOR SAFETY PUBLIC POLICY AND RISK MANAGEMENT}

Bjarne Jansson. Karolinska Institutet, Stockholm, Sweden

10.1136/injuryprev-2016-042156.625

Five elements could be identified as main components in a typology for safety policy and risk management. Policy-making should be used to provide long-term safety planning in a defined political jurisdiction area. Trauma surveillance is based on the development and maintenance of supportive systems in trauma emergency care departments. Risk management includes a number of organisations for developing supportive environments. Settings are channels and mechanisms of influence for reaching defined populations. Community involvement should guarantee peoples empowerment in the development of safe communities. 